\title{
MicroRNA-24 inhibits the proliferation and migration of endothelial cells in patients with atherosclerosis by targeting importin- $\alpha 3$ and regulating inflammatory responses
}

\author{
YE ZHENG ${ }^{1,2}$, YONGXING LI ${ }^{2}$, GANG LIU $^{3}$, XIANGQIAN QI ${ }^{4}$ and XUFEN CAO ${ }^{2}$ \\ ${ }^{1}$ Graduate School of Tianjin Medical University, Tianjin 300070; ${ }^{2}$ Department of Cardiovascular Medicine, \\ Cangzhou Central Hospital, Cangzhou, Hebei 061001; ${ }^{3}$ Department of Cardiovascular Medicine, First \\ Hospital of Hebei Medical University, Shijiazhuang, Hebei 050000; ${ }^{4}$ Department of Cardiovascular \\ Medicine, Tianjin TEDA International Cardiovascular Hospital, Tianjin 300000, P.R. China
}

Received September 11, 2016; Accepted May 19, 2017

DOI: $10.3892 / \mathrm{etm} .2017 .5355$

\begin{abstract}
The aim of the present study was to measure the level of microRNA (miRNA or miR)-24 in the serum of patients with atherosclerosis and to investigate the effect of miR-24 on the expression of importin- $\alpha 3$ and tumor necrosis factor (TNF)- $\alpha$, as well as the proliferation and migration of vascular endothelial cells. A total of 30 patients with atherosclerosis admitted to hospital between January and June 2016 were enrolled in the present study; 30 healthy subjects with a similar age range were enrolled as controls. Peripheral blood $(10 \mathrm{ml})$ was collected from all participants. Human umbilical vein endothelial cells (HUVECs) were transfected with miR-24 mimic using Lipofectamine 2000. TargetScan was used to elucidate whether importin- $\alpha 3$ (KPNA4) was a target gene of miR-24. Expression levels of miR-24 and mRNAs were measured using reverse transcription-quantitative polymerase chain reaction, and protein expression was determined using western blotting. Cell Counting Kit 8 assay was used to assess the proliferation of HUVECs, and a Transwell assay was performed to detect the migration of HUVECs. Expression of miR-24 in peripheral blood from patients with atherosclerosis was significantly lower when compared with healthy subjects $(\mathrm{P}<0.05)$. Overexpression of miR-24 was demonstrated to significantly inhibit the transcription and translation of the importin- $\alpha 3$ gene $(\mathrm{P}<0.05)$ and negatively regulate the expression of endothelial inflammatory factor TNF- $\alpha(\mathrm{P}<0.05)$.
\end{abstract}

Correspondence to: Dr Ye Zheng, Department of Cardiovascular Medicine, Cangzhou Central Hospital, 16 Xinhua West Road, Cangzhou, Hebei 061001, P.R. China

E-mail: yec333@126.com

Dr Xiangqian Qi, Department of Cardiovascular Medicine, Tianjin TEDA International Cardiovascular Hospital, 61 Third Avenue, Tianjin 300000, P.R. China

E-mail: qixq@tedaich.com

Key words: atherosclerosis, microRNA, importin- $\alpha 3$
Furthermore, overexpression of miR-24 significantly inhibited the proliferation and migration of HUVECs $(\mathrm{P}<0.05)$, and miR-24 knockdown significantly promoted these processes $(\mathrm{P}<0.05)$. The results of the present study suggest that miR-24 exerts its effect in atherosclerosis by blocking the nuclear factor- $\kappa \mathrm{B}$ signaling pathway, regulating inflammation in endothelial cells, and inhibiting the proliferation and migration of vascular endothelial cells.

\section{Introduction}

Atherosclerosis is the most common lesion that occurs in the cardiovascular system, with a high incidence worldwide (1). The occurrence of atherosclerotic lesions is a chronic and complex process that involves interactions among various factors, such as local hemodynamics (2), arterial wall cells (3), the extracellular matrix (4), the environment (5) and genetics (6). Vascular endothelial injury, phenotypic transformation of smooth muscle cells, lipid absorption by monocytes or macrophages, and inflammatory mediator release are important processes in the development of atherosclerosis (7-9). The nuclear factor $\kappa$-light-chain-enhancer of activated $\mathrm{B}$ cells $(\mathrm{NF}-\kappa \mathrm{B})$ signaling pathway is considered a key signaling pathway that mediates vascular endothelial cell injury and the release of inflammatory mediators, such as vascular cell adhesion molecule-1 (VCAM-1) and intercellular adhesion molecule-1 (ICAM-1) (10). An important step in the development of atherosclerosis is the inflammation of the vascular endothelial cell layer (11). Importin- $\alpha 3$ is a key protein that is associated with the nuclear transfer of $\mathrm{NF}-\kappa \mathrm{B}$, which is important in the occurrence of inflammation (12). Importin- $\alpha 3$ was therefore chosen as a target gene in the present study. In addition to being a proinflammatory factor, tumor necrosis factor (TNF)- $\alpha$ also activates $\mathrm{NF}-\kappa \mathrm{B}$, which then initiates a cascade reaction of cytokines, further aggravating inflammatory responses and apoptosis in tissues (13).

microRNA (miRNA or miR) are a class of endogenous non-coding RNA that regulate a variety of cellular mechanisms, including inflammation, cytothesis and lipid metabolism, as well as participating in the development of 
atherosclerosis (14). For example, miR-155 regulates multiple functions of macrophages, including inflammation, lipid absorption and apoptosis $(15,16)$. In addition, low-density lipoprotein and mildly oxidized low-density lipoprotein are able to induce the expression of miR-155 in macrophages $(15,16)$. miR-342-5p promotes the expression of miR-155 via V-protein kinase B murine thymoma viral oncogene homolog 1 , and facilitates the expression of inflammatory mediators, such as nitric oxide, TNF- $\alpha$ and interleukin-6 (17). Furthermore, miR-33 (18), miR-122 (19) and miR-27a (20) affect the development of atherosclerosis by participating in lipid metabolism. It has been reported that miR-24 participates in pathophysiological processes, including tumor formation (21) and ischemic reperfusion injury (22). However, the role of miR-24 in atherosclerosis has rarely been reported. Maegdefessel et al (23) reported that miR-24 limits aortic vascular inflammation and murine abdominal aneurysm development. Murata et al (24) demonstrated that miR-24 in plasma may function as a biomarker for rheumatoid arthritis. In the present study, serum expression of miR-24 in elderly patients with atherosclerosis was assessed, and the effect of miR-24 on importin- $\alpha 3$, TNF- $\alpha$ and the proliferation and migration ability of vascular endothelial cells was investigated.

\section{Materials and methods}

Patients. A total of 30 patients with atherosclerosis admitted to Cangzhou Central Hospital between January and June 2016 were enrolled in the present study, including 20 males

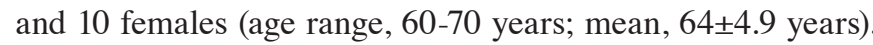
Inclusion criteria were as follows: Significantly elevated blood lipids and a positive diagnosis of atherosclerotic plaque formation using peripheral vascular ultrasound examinations. A total of 30 healthy subjects were enrolled as controls, including 20 males and 10 females (age range, 60-70 years; mean, $63 \pm 5.6$ years). Healthy subjects had no history of hypertension, diabetes, atherosclerosis or tumors. Peripheral blood $(10 \mathrm{ml})$ was collected from all patients and healthy subjects, and centrifuged at 1,200 x g and 20-22 ${ }^{\circ} \mathrm{C}$ for $8 \mathrm{~min}$ to separate serum. All procedures were approved by the Ethics Committee of Cangzhou Central Hospital (Cangzhou, China). Written informed consent was obtained from all participants or their families.

Cells. Human umbilical vein endothelial cells (HUVECs; Cell Bank of Chinese Academy of Sciences, Shanghai, China) were cultured in Dulbecco's modified Eagle's medium (DMEM) supplemented with $10 \%$ fetal bovine serum (Thermo Fisher Scientific, Inc., Waltham, MA, USA) at $37^{\circ} \mathrm{C}$ in an atmosphere containing $5 \% \mathrm{CO}_{2}$. Cells were seeded in culture plates at $3 \times 10^{5}$ cells/well and cultured for $24 \mathrm{~h}$. HUVECs were randomly divided into the has-miR-24 mimic group (transfected with has-miR-24 mimic; Guangzhou RiboBio Co., Ltd., Guangzhou, China) or negative control group (untransfected). When cells reached $50 \%$ confluency they were used for transfection. In the first vial, $7.5 \mu 1$ small RNA fragments was mixed with $125 \mu \mathrm{l}$ serum-free DMEM. In the second vial, $7.5 \mu$ l liposome (Lipofectamine 2000; Thermo Fisher Scientific, Inc.) was mixed with $125 \mu \mathrm{l}$ serum-free DMEM. After standing for $5 \mathrm{~min}$, the two vials were combined and left to stand at room temperature for $20 \mathrm{~min}$. The mixtures were subsequently added to cells for incubation at $37^{\circ} \mathrm{C}$ for $6 \mathrm{~h}$. The medium was subsequently replaced with DMEM containing $10 \%$ fetal bovine serum and cultivated at $37^{\circ} \mathrm{C}$ for $48 \mathrm{~h}$, at which point the cells were collected for further assays.

Reverse transcription-quantitative polymerase chain reaction $(R T-q P C R)$. Serum $(1 \mathrm{ml})$ was mixed with $1 \mathrm{ml}$ TRIzol (Thermo Fisher Scientific, Inc.) for lysis and total RNA was extracted using the phenol chloroform method. The purity of RNA was determined by A260/A280 using ultraviolet spectrophotometry (Nanodrop ND1000; Thermo Fisher Scientific, Inc.). cDNA was obtained by RT using a PrimeScript ${ }^{\mathrm{TM}} \mathrm{RT}$ reagent kit with gDNA Eraser (Takara Biotechnology Co., Ltd., Dalian, China) from $1 \mu \mathrm{g}$ RNA and stored at $-20^{\circ} \mathrm{C}$. The temperature protocol was as follows: $42^{\circ} \mathrm{C}$ for $2 \mathrm{~min}, 37^{\circ} \mathrm{C}$ for $15 \mathrm{~min}$ and $85^{\circ} \mathrm{C}$ for $5 \mathrm{sec}$.

Expression of miR-24 was determined using a SYBR PrimeScript miRNA RT-PCR Kit (Takara Biotechnology Co., Ltd.), with U6 as an internal reference. The reaction system (25 $\mu \mathrm{l}$ ) contained $12.5 \mu \mathrm{l}$ SYBR Premix Ex Taq, $1 \mu \mathrm{l}$ of each forward primer (miR-24, 5'-GCAGATGGCTCAGTTCAG CAG-3'; U6, 5'-TGCGGGTGCTCGCTTCGGCAGC-3'), $1 \mu 1$ Uni-miR qPCR primer (cat no. 638315; Takara Biotechnology

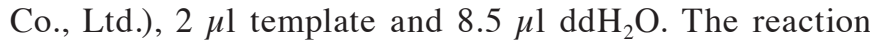
protocol was as follows: Initial denaturation at $95^{\circ} \mathrm{C}$ for $10 \mathrm{~min}$, followed by 40 cycles of $95^{\circ} \mathrm{C}$ for $15 \mathrm{sec}$ and $60^{\circ} \mathrm{C}$ for $1 \mathrm{~min}$ (iQ5; Bio-Rad Laboratories, Inc., Hercules, CA, USA). The $2^{-\Delta \Delta \mathrm{Cq}}$ method was used to calculate the relative expression of miR-24 against U6 (25). Each sample was tested in triplicate.

A SYBR-Green RT-qPCR kit (Kapa Biosystems, Inc., Wilmington, MA, USA) was used to detect the mRNA expression of importin- $\alpha 3$ and TNF- $\alpha$, using GAPDH as an internal reference. The reaction system $(20 \mu \mathrm{l})$ was composed of $10 \mu \mathrm{l}$ SYBR Premix Ex Taq, $0.5 \mu 1$ upstream primer (importin- $\alpha 3$, 5'-CTGTGTACGAGAGCGTGGTT-3'; TNF- $\alpha, 5$ '-GGAGAA GGGTGACCGACTCA-3'; and GAPDH, 5'-AAGGTGAAG GTCGGAGTCA-3'), $0.5 \mu$ l downstream primer (importin- $\alpha 3$, 5'-TATCAGCCCCCTGAAGGTGA-3'; TNF- $\alpha$, 5'-CTGCCC AGACTCGGCAA-3'; and GAPDH, 5'-GGAAGATGGTGA

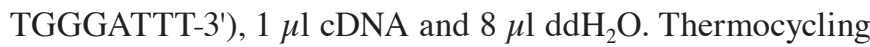
conditions were as follows: Initial denaturation at $95^{\circ} \mathrm{C}$ for $10 \mathrm{~min}$, followed by 40 cycles of denaturation at $95^{\circ} \mathrm{C}$ for $1 \mathrm{~min}$, annealing at $60^{\circ} \mathrm{C}$ for $40 \mathrm{sec}$ and elongation at $72^{\circ} \mathrm{C}$ for $30 \mathrm{sec}$, and final elongation at $72^{\circ} \mathrm{C}$ for $1 \mathrm{~min}$. The $2^{-\Delta \Delta \mathrm{Cq}}$ method was used to calculate the relative expression of importin- $\alpha 3$ and TNF- $\alpha$ mRNA against GAPDH (25). Each sample was tested in triplicate.

Western blot analysis. HUVECs were seeded into 6-well plates at a density of $1 \times 10^{6}$ cells/well. At $48 \mathrm{~h}$ after transfection, the cells were collected and mixed with $100 \mu \mathrm{l}$ precooled radioimmunoprecipitation assay lysis buffer (Beyotime Institute of Biotechnology, Haimen, China) containing $1 \mathrm{mM}$ phenylmethylsulfonyl fluoride (Beyotime Institute of Biotechnology) for lysis of $15 \mathrm{~min}$ at $4^{\circ} \mathrm{C}$. Then, the mixture was centrifuged at $12,000 \mathrm{x} \mathrm{g}$ and $4^{\circ} \mathrm{C}$ for $5 \mathrm{~min}$. The supernatant was used to determine protein concentration using a bicinchoninic acid protein concentration determination kit (RTP7102; Real-Times Biotechnology Co., Ltd., Beijing, China). Protein 
samples $(50 \mu \mathrm{g})$ were mixed with 2X SDS loading buffer and denatured in a boiling water bath for $5 \mathrm{~min}$. Following this, the samples $(10 \mu \mathrm{l})$ were separated by $10 \%$ SDS-PAGE at $100 \mathrm{~V}$. Resolved proteins were transferred to polyvinylidene difluoride membranes on ice ( $300 \mathrm{~mA}, 1.5 \mathrm{~h}$ ) and blocked with $5 \mathrm{~g} / \mathrm{l}$ skimmed milk at room temperature for $1 \mathrm{~h}$. The membranes were subsequently incubated with goat anti-human importin- $\alpha 3$ polyclonal primary antibody (1:1,000; cat no. ab6039), rabbit anti-human TNF- $\alpha$ polyclonal primary antibody $(1: 1,000$; cat no. ab9635) and rabbit anti-human GAPDH primary antibody (1:2,000; cat no. ab9485, all Abcam, Cambridge, UK) at $4^{\circ} \mathrm{C}$ overnight. Following washing with PBST three times of $15 \mathrm{~min}$, the membranes were incubated with polyclonal goat anti-rabbit horseradish peroxidase-conjugated secondary antibody (1:1,000; cat no. ab205718, Abcam) for $1 \mathrm{~h}$ at room temperature. Membranes were washed three times with PBST three times for $15 \mathrm{~min}$ and developed using an enhanced chemiluminescence detection kit (Sigma-Aldrich; Merck KGaA, Darmstadt, Germany). Image Lab v3.0 software (Bio-Rad Laboratories, Inc.) was used to acquire and analyze imaging signals. Expression of importin- $\alpha 3$ and TNF- $\alpha$ protein was calculated relative to GAPDH.

Cell-Counting Kit 8 (CCK-8) assay. HUVECs were seeded at 5,000 cells/well in 96-well plates for transfection. At $48 \mathrm{~h}$ after transfection, HUVECs were subjected to CCK- 8 assay for the detection of proliferation. At 24, 48 and $72 \mathrm{~h}$, DMEM (Hyclone; GE Healthcare Life Sciences, Logan, UT, USA) was discarded, the cells were washed with twice with PBS and 10\% CCK-8 reaction reagent (Beyotime Institute of Biotechnology) diluted in DMEM medium was added. Following incubation at $37^{\circ} \mathrm{C}$ for $2 \mathrm{~h}$, the absorbance of each well was measured at $450 \mathrm{~nm}$ using $600 \mathrm{~nm}$ as a reference for plotting cell proliferation curves. A total of five replicate wells were assayed for each group and the mean values were calculated.

Transwell assay. HUVECs were seeded at $3 \times 10^{5} /$ well into 6 -well plates for transfection. At $48 \mathrm{~h}$ after transfection, Transwell chambers $(8 \mu \mathrm{m}$ diameter and 24 wells; Corning Inc., Corning, NY, USA) were used to evaluate the migration ability of HUVECs. Transfected cells were collected by trypsin digestion, and resuspended at a density of $1 \times 10^{5}$ cells $/ \mathrm{ml}$ using DMEM. The cell suspension $(100 \mu \mathrm{l})$ was added into the upper chamber. In the lower chamber, $600 \mu \mathrm{l}$ DMEM medium supplemented with $10 \%$ fetal bovine serum was added. Following incubation at $37^{\circ} \mathrm{C}$ for $24 \mathrm{~h}$, cells in the upper chamber were wiped with a cotton swab. The chamber was subsequently fixed using $95 \%$ ethanol for $10 \mathrm{~min}$ at room temperature. Following staining with $0.1 \%$ crystal violet at $22^{\circ} \mathrm{C}$ for $30 \mathrm{~min}$, the number of cells in 10 fields were counted under a light microscope (magnification, x200).

Dual luciferase reporter assay. Bioinformatics prediction is a powerful tool for studying the functions of miRNA. To elucidate whether importin- $\alpha 3$ (KPNA4) was a target gene of miR-24, TargetScan (targetscan.org) was used to predict miRNA molecules that may regulate importin- $\alpha 3$, and miR-24 was identified as a potential regulator of importin- $\alpha 3$. According to the bioinformatics results, wild-type (WT) and mutant seed regions of miR-24 in the 3'-untranslated region

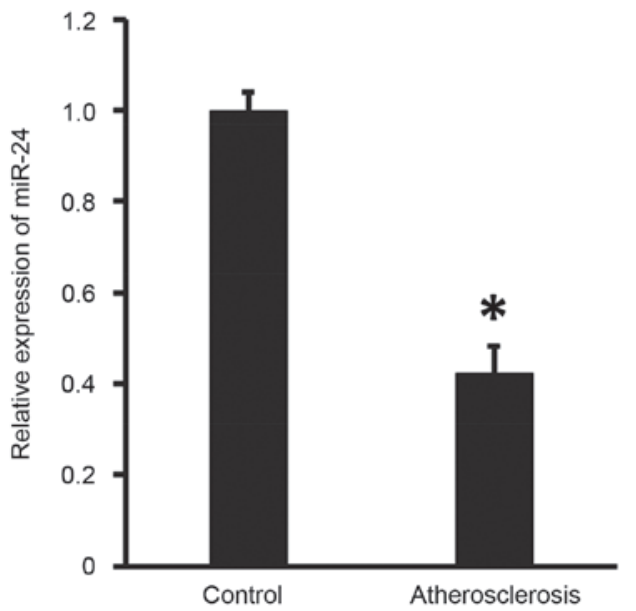

Figure 1. Expression of miR-24 in peripheral blood from healthy control subjects and patients with atherosclerosis. Expression of miR-24 was determined by reverse transcription-quantitative polymerase chain reaction. ${ }^{*} \mathrm{P}<0.05$ vs. control. miR, microRNA.

\section{3' gacaaggacgacuugACUCGGu 5' hsa-miR-24 IIIII \\ 5' uaagucaaaggaaaaUGAGCCc 3' Importin- 33 (NM_002268)}

Figure 2. Bioinformatics prediction of direct interactions between miR-24 and importin- $\alpha 3$ using TargetScan (targetscan.org). miR, microRNA.

(UTR) of importin- $\alpha 3$ gene were chemically synthesized in vitro, added to SpeI and HindIII restriction sites, and cloned into pMIR-REPORT luciferase reporter plasmids (Promega Corporation, Madison, WI, USA). Plasmids $(0.5 \mu \mathrm{g})$ with WT or mutant 3'-UTR DNA sequences were co-transfected with miR-24 mimic (100 nM; Sangon Biotech Co., Ltd., Shanghai, China) into HEK293T cells (ATCC, Manassas, VA, USA). Following cultivation at $37^{\circ} \mathrm{C}$ for $24 \mathrm{~h}$, cells were lysed using a dual luciferase reporter assay kit (Promega Corporation) according to the manufacturer's manual, and fluorescence intensity was measured using GloMax 20/20 illuminometer (Promega Corporation). Using Renilla fluorescence activity as an internal reference, the fluorescence values of each group of cells were measured.

Statistical analysis. Statistical analysis was performed using SPSS v16.0 (SPSS, Inc., Chicago, IL, USA). Measurement data were expressed as the mean \pm standard deviation. Two groups of data were compared using an independent samples t-test. Single factor analysis of variance was used to compare the means of multiple samples followed by a Tukey's post hoc test. $\mathrm{P}<0.05$ was considered to indicate a statistically significant difference.

\section{Results}

Expression of miR-24 in peripheral blood from patients with atherosclerosis is abnormal. To measure the expression of miR-24 in the peripheral blood, RT-qPCR was performed. The results demonstrated that the level of miR-24 in patients with atherosclerosis was significantly lower than that of the controls ( $\mathrm{P}<0.05$; Fig. 1). These findings suggests that miR-24 expression is abnormal in patients with atherosclerosis. 
A

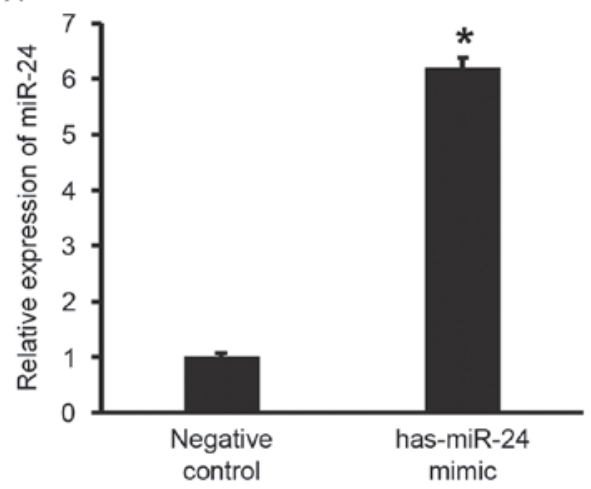

C

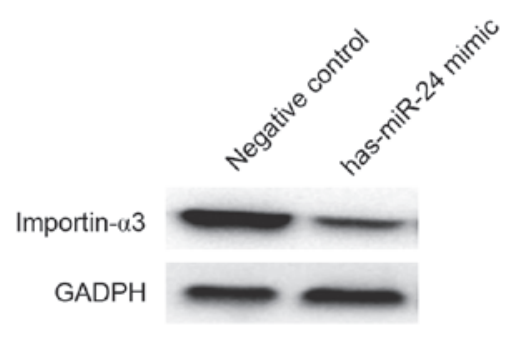

B

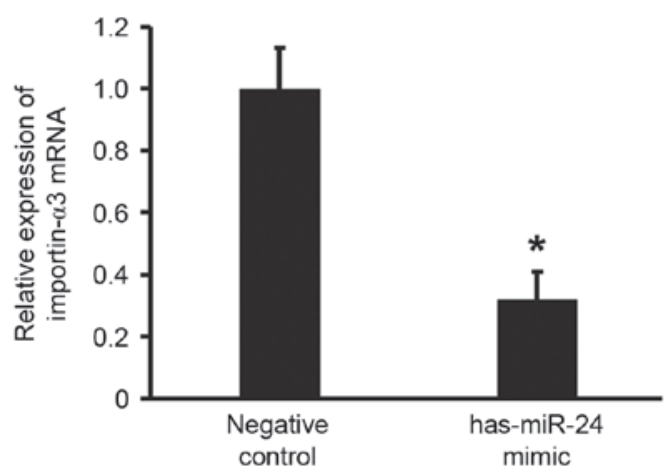

D

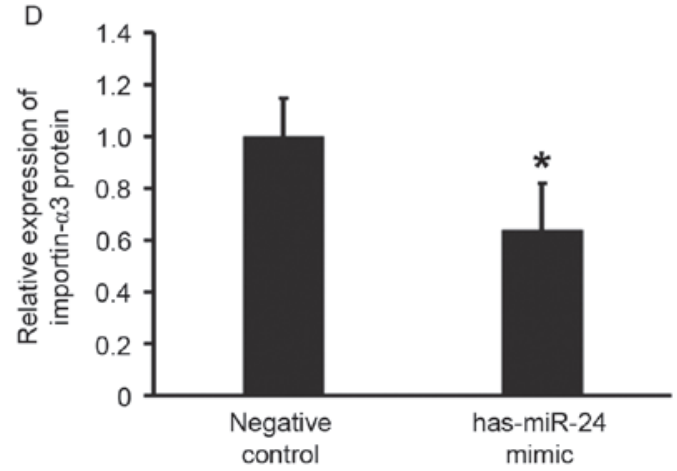

Figure 3. Effect of miR-24 on the expression of importin- $\alpha 3$ in HUVECs. (A) Relative expression of miR-24, (B) importin- $\alpha 3$ mRNA and (C and D) importin- $\alpha 3$ protein in HUVECs from the negative control and miR-24 mimic groups. Reverse transcription-quantitative polymerase chain reaction was used to determine the expression of miR-24 and importin- $\alpha 3$ mRNA, and western blotting was employed to measure importin- $\alpha 3$ protein expression. ${ }^{*} \mathrm{P}<0.05$ vs. negative control group. miR, microRNA; HUVECs, human umbilical vein epithelial cells.

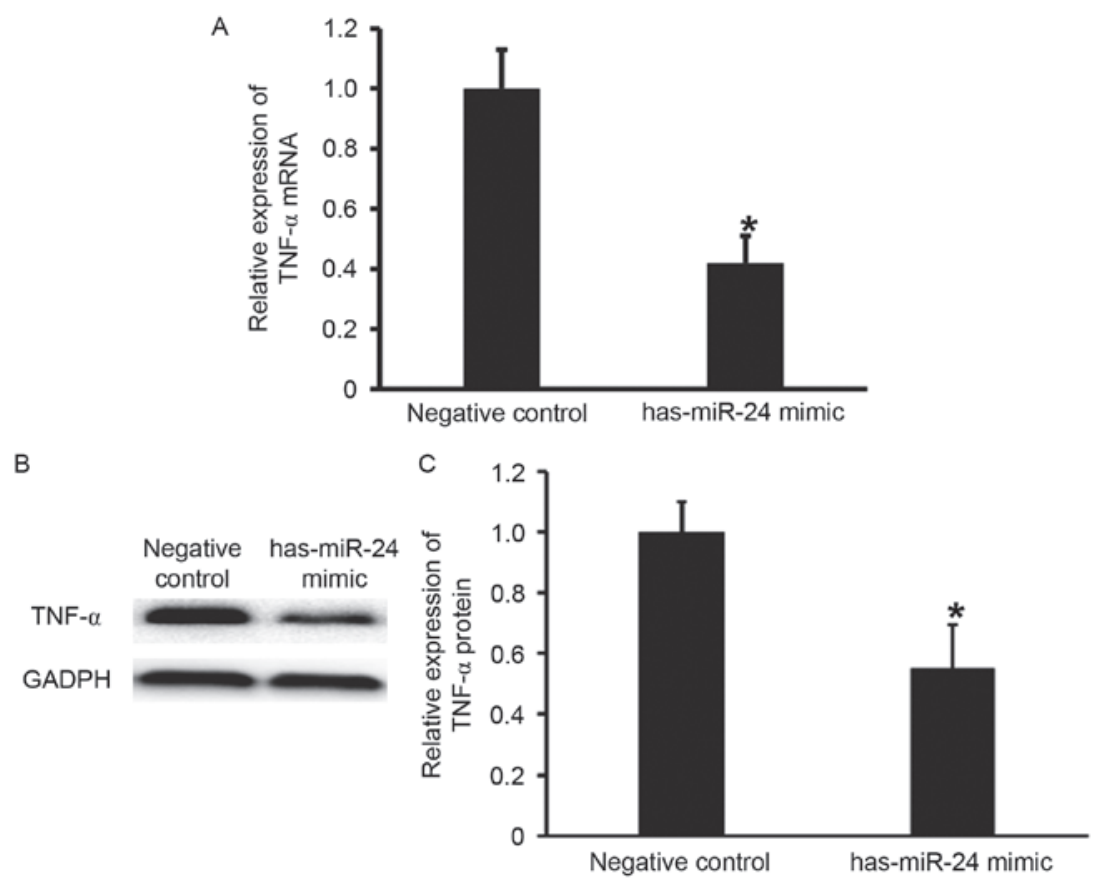

Figure 4. Effect of miR-24 on the expression of TNF- $\alpha$ in HUVECs. (A) Relative expression of TNF- $\alpha$ mRNA in HUVECs of negative control and miR-24 mimic groups. (B and C) Relative expression of TNF- $\alpha$ protein in HUVECs of negative control and miR-24 mimic groups. Reverse transcription-quantitative polymerase chain reaction was used to determine the expression of TNF- $\alpha$ mRNA, and western blotting was employed to measure TNF- $\alpha$ protein expression. ${ }^{\text {"P }}<0.05$ vs. negative control group. miR, microRNA; TNF, tumor necrosis factor; HUVECs, human umbilical vein epithelial cells.

Overexpression of miR-24 inhibits the transcription and translation of importin- $\alpha 3$ gene. To predict whether miR-24 is able to target importin- $\alpha 3$, TargetScan was used. The data demonstrated that miR-24 is able to bind with the 3'-UTR of miR-24 (Fig. 2). To test whether miR-24 regulates the expression of importin- $\alpha 3$, HUVECs were transfected with miR-24 


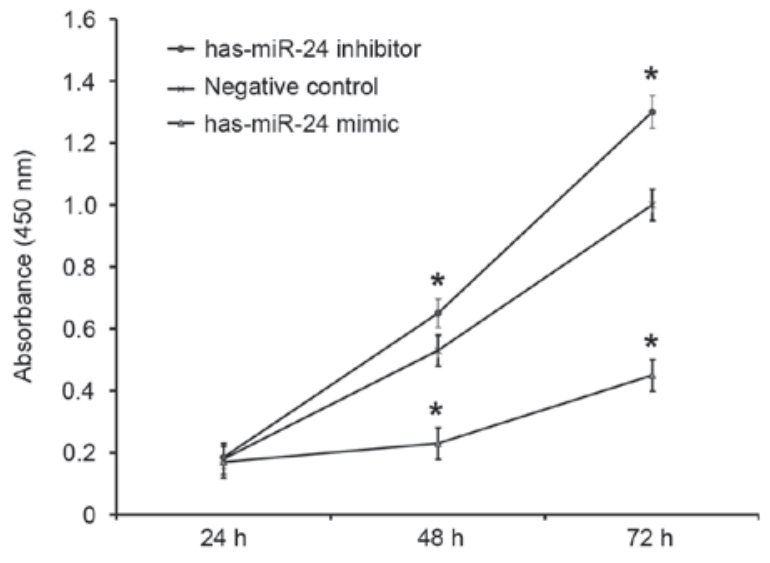

Figure 5. Proliferation of HUVECs at 24, 48, and $72 \mathrm{~h}$ after transfection with miR-24 mimics or inhibitors. Cell Counting Kit- 8 assay was used to determine the proliferation of the cells. Absorbance of each well was measured at $450 \mathrm{~nm}$ with a microplate reader and cell proliferation curves were plotted ${ }^{*} \mathrm{P}<0.05$ vs. negative control group. miR, microRNA; HUVECs, human umbilical vein epithelial cells.

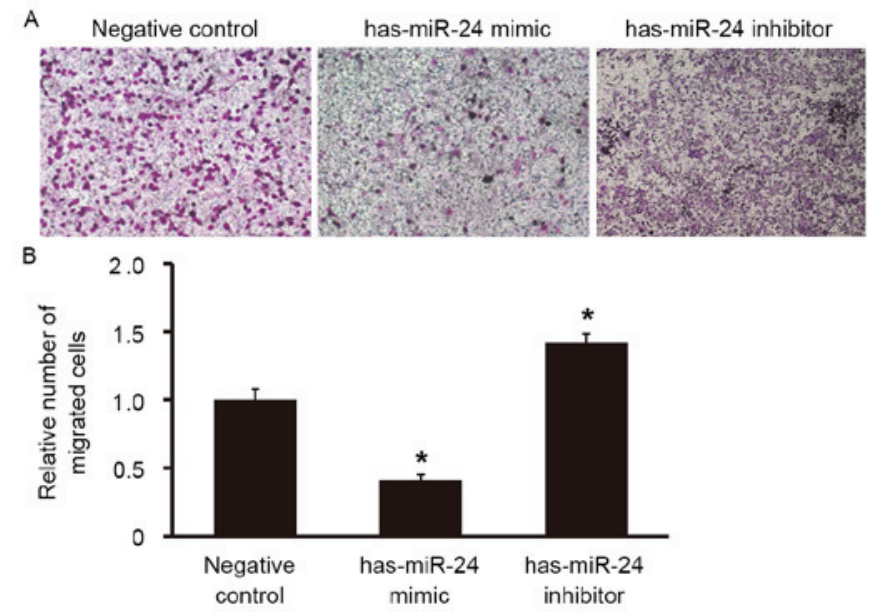

Figure 6. Effect of miR-24 on the migration ability of HUVECs Transwell assay was used to determine the migration ability of the cells. (A) Representative images the number of migrated cells in the lower chamber (magnification, $\mathrm{x} 100$ ) and (B) subsequent relative analysis. ${ }^{*} \mathrm{P}<0.05$ vs. negative control group. miR, microRNA; HUVEC, human umbilical vein epithelial cell.

mimic. The results showed that that HUVECs transfected with miR-24 mimics had significantly increased miR-24 levels when compared with the negative control group $(\mathrm{P}<0.05$; Fig. $3 \mathrm{~A})$. In addition, the expression of importin- $\alpha 3$ mRNA and protein in HUVECs transfected with miR-24 mimics was significantly lower than that of the negative control ( $\mathrm{P}<0.05$; Fig. 3B-D). These results indicate that overexpression of miR-24 inhibits the transcription and translation of importin- $\alpha 3$ gene.

miR-24 negatively regulates the expression of endothelial inflammatory factor TNF- $\alpha$. To examine the effect of miR-24 on the expression of TNF- $\alpha$, RT-qPCR and western blotting were performed. TNF- $\alpha$ mRNA and protein expression levels were significantly lower in HUVECs transfected with miR-24 mimic, when compared with the negative control group $(\mathrm{P}<0.05$; Fig. 4). These results suggest that miR-24 negatively regulates the expression of endothelial inflammatory factor, TNF- $\alpha$.

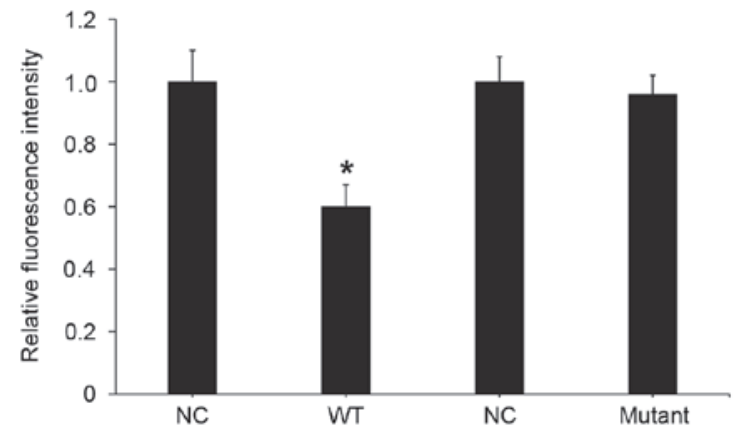

Figure 7. Fluorescence values of HEK293T cells transfected with WT or mutant 3'-untranslated region DNA sequences of importin- $\alpha 3$ and miR-24 mimic. A dual luciferase reporter assay was used to evaluate the interaction between miR-24 and importin- $\alpha 3$. "P<0.05 vs. NC. WT, wild type; miR, microRNA; NC, negative control.

Overexpression of miR-24 inhibits HUVEC proliferation and miR-24 knockdown promotes it. To determine how miR-24 affects the proliferation of HUVECs, a CCK- 8 assay was employed. The absorbance of HUVECs transfected with miR-24 mimic was significantly lower than that of the negative control group at 48 and $72 \mathrm{~h}(\mathrm{P}<0.05$; Fig. 5). By contrast, the absorbance of HUVECs transfected with miR-24 inhibitor was significantly higher compared with the negative control group at 48 and $72 \mathrm{~h}(\mathrm{P}<0.05$; Fig. 5). This suggests that overexpression of miR-24 inhibits the proliferation of endothelial cells, whereas the inhibition of miR-24 expression promotes.

Overexpression of miR-24 reduces the migration ability of endothelial cells, but inhibition of miR-24 expression promotes it. To examine the effect of $\mathrm{miR}-24$ on the migration ability of HUVECs, a Transwell assay was used. The number of cells that migrated to the lower chamber was significantly lower in the miR-24 mimic group compared with the negative control group $(\mathrm{P}<0.05$; Fig. 6$)$, whereas the number of cells that migrated to the lower chamber in miR-24 inhibitor group was significantly higher $(\mathrm{P}<0.05$; Fig. 6$)$. This suggests that overexpression of miR-24 reduces the migration ability of endothelial cells, whereas miR-24 knockdown promotes it.

miR-24 downregulates the expression of importin- $\alpha 3$ by binding with the 3'-UTR of importin- $\alpha 3$ gene. To understand whether miR-24 directly targets importin- $\alpha 3$, a dual luciferase reporter assay was performed. Transfection with miR-24 mimics and pMIR-REPORT-wild type importin- $\alpha 3$ led to a significant decrease in fluorescence intensity, as compared with the negative control $(\mathrm{P}<0.05$; Fig. 7). Transfection with miR-24 mimic and pMIR-REPORT-mutant importin- $\alpha 3$ had no significant effect on fluorescence intensity. These results suggests that miR-24 downregulates the expression of importin- $\alpha 3$ by binding with the 3 '-UTR of the importin- $\alpha 3$ gene.

\section{Discussion}

Atherosclerosis is the pathological basis of various types of cardiac and cerebral vascular diseases (26). The most important processes in the occurrence and development of atherosclerosis include i) vascular endothelial cell injury and 
inflammatory activation; ii) the proliferation and migration of endothelial/smooth muscle cells; and iii) the release of inflammatory mediators stimulated by macrophage activation (27-30). It has been reported that miR-24 expression is downregulated in atherosclerotic plaques, and miR-24 participates in the formation of atherosclerosis primarily by targeting and inhibiting matrix metalloproteinase-14 (31). In the present study, it was demonstrated that miR-24 expression is significantly lower in patients with atherosclerosis, as compared with healthy subjects. Bioinformatics revealed that the importin- $\alpha 3$ gene is a potential target gene of miR-24. A previous study reported that the importin protein family $(\alpha 1, \alpha 3, \alpha 4, \alpha 5, \alpha 6$ and $\alpha 7)$ is an important class of transport proteins associated with the nuclear transfer of $\mathrm{NF}-\kappa \mathrm{B}$, which is a key process in the activation of the $N F-\kappa B$ signaling pathway (32). The results of the present study demonstrate that miR-24 inhibits the expression of importin- $\alpha 3$ and NF- $\kappa \mathrm{B}$ signaling pathway-mediated inflammatory factor, TNF- $\alpha$. Naqvi et al (33) demonstrated that TNF- $\alpha$ is also a target gene of miR-24. Combined with the results of the present study, this suggests that miR-24 may regulate inflammatory processes by simultaneously targeting importin- $\alpha 3$ and TNF- $\alpha$ in respect to the mechanism of atherosclerosis. Therefore, miR-24 reduces the activation of vascular endothelial cells and inflammatory responses. Maegdefessel et al (23) reported that miR-24 inhibits the development of aortic vascular inflammation and abdominal aortic aneurysm in mice by targeting chitinase 3-like 1. Xiang et al (34) demonstrated that patients with diabetes have low miR-24 expression, which suggests potential thrombotic events in these patients. The present study indicates that endothelial cell activation and inflammatory responses regulated by miR-24 participate in the development of atherosclerosis.

miRNAs have previously been reported to participate in the regulation of vascular endothelial cell functions, and have important roles in the development of atherosclerosis; for example, enhanced expression of miR-221 and miR-222 in human arterial endothelial cells causes reduced levels and activity of nitric oxide synthase, leading to cell dysfunction (35). In addition, reduced miR-126 and increased miR-125b expression results in increased endothelial inflammatory response protein secretion (36). miR-29 affects the production of collagen and elastin, and has important roles in maintaining arterial structural integrity (37). The results of the present study indicate that overexpression of miR-24 inhibits the proliferation and migration of endothelial cells. Lal et al (38) reported that miR-24 targets E2F2 and inhibits the proliferation of erythroleukemia K562 cells. Similarly, Amelio et al (39) demonstrated that miR-24 regulates the migration of human keratinocytes and mouse epidermal cells, suggesting that miR-24 has important roles in the regulation of proliferation, invasion and migration of cells.

In conclusion, the results of the present study demonstrate that miR-24 inhibits the proliferation and migration of endothelial cells by targeting importin- $\alpha 3$ and regulating inflammatory responses in endothelial cells. Low levels of miR-24 in the peripheral blood are associated with atherosclerosis progression. Furthermore, miR-24 may provide a novel strategy and direction for the clinical treatment and research on atherosclerosis. Further investigation is required to elucidate the underlying mechanism of inflammation in atherosclerosis and to explore the mechanism of abnormal expression of miR-24 in the blood of patients with atherosclerosis.

\section{Acknowledgements}

The present study was supported by the Hebei Science and Technology Support Program Key Projects (grant no. $16277707 \mathrm{D})$.

\section{References}

1. Beckman JA, Creager MA and Libby P: Diabetes and atherosclerosis: Epidemiology, pathophysiology, and management. JAMA 287: 2570-2581, 2002

2. Malek AM, Alper SL and Izumo S: Hemodynamic shear stress and its role in atherosclerosis. JAMA 282: 2035-2042, 1999.

3. Ross R and Glomset JA: Atherosclerosis and the arterial smooth muscle cell: Proliferation of smooth muscle is a key event in the genesis of the lesions of atherosclerosis. Science 180: 1332-1339, 1973.

4. Katsuda S and Kaji T: Atherosclerosis and extracellular matrix. J Atheroscler Thromb 10: 267-274, 2003.

5. Morland K, Wing S and Diez Roux A: The contextual effect of the local food environment on residents' diets: The atherosclerosis risk in communities study. Am J Public Health 92: 1761-1767, 2002.

6. Fox CS, Polak JF, Chazaro I, Cupples A, Wolf PA, D'Agostino RA and O'Donnell CJ; Framingham Heart Study: Genetic and environmental contributions to atherosclerosis phenotypes in men and women: Heritability of carotid intima-media thickness in the Framingham Heart Study. Stroke 34: 397-401, 2003.

7. Fenyo IM and Gafencu AV: The involvement of the monocytes/macrophages in chronic inflammation associated with atherosclerosis. Immunobiology 218: 1376-1384, 2013.

8. Gomez D and Owens GK: Smooth muscle cell phenotypic switching in atherosclerosis. Cardiovasc Res 95: 156-164, 2012.

9. Munro JM and Cotran RS: The pathogenesis of atherosclerosis: Atherogenesis and inflammation. Lab Invest 58: 249-261, 1988.

10. de Winther MP, Kanters E, Kraal G and Hofker MH: Nuclear factor kappaB signaling in atherogenesis. Arterioscler Thromb Vasc Biol 25: 904-914, 2005.

11. Rajendran P, Rengarajan T, Thangavel J, Nishigaki Y, Sakthisekaran D, Sethi G and Nishigaki I: The vascular endothelium and human diseases. Int J Biol Sci 9: 1057-1069, 2013.

12. Fagerlund R, Kinnunen L, Köhler M, Julkunen I and Melén K: $\mathrm{NF}-\{$ kappa $\} \mathrm{B}$ is transported into the nucleus by importin \{alpha\}3 and importin \{alpha\}4. J Biol Chem 280: 15942-15951, 2005.

13. Bouwmeester T, Bauch A, Ruffner H, Angrand PO, Bergamini G, Croughton K, Cruciat C, Eberhard D, Gagneur J, Ghidelli S, et al: A physical and functional map of the human TNF-alpha/NF-kappaB signal transduction pathway. Nat Cell Biol 6: 97-105, 2004.

14. Rayner KJ, Fernandez-Hernando C and Moore KJ: MicroRNAs regulating lipid metabolism in atherogenesis. Thromb Haemost 107: 642-647, 2012.

15. Koch M, Mollenkopf HJ, Klemm U and Meyer TF: Induction of microRNA-155 is TLR- and type IV secretion system-dependent in macrophages and inhibits DNA-damage induced apoptosis. Proc Natl Acad Sci USA 109: E1153-E1162, 2012.

16. Nazari-Jahantigh M, Wei Y, Noels H, Akhtar S, Zhou Z, Koenen RR, Heyll K, Gremse F, Kiessling F, Grommes J, et al: MicroRNA-155 promotes atherosclerosis by repressing Bcl6 in macrophages. J Clin Invest 122: 4190-4202, 2012.

17. Wei Y, Nazari-Jahantigh M, Chan L, Zhu M, Heyll K, Corbalán-Campos J, Hartmann P, Thiemann A, Weber C and Schober A: The microRNA-342-5p fosters inflammatory macrophage activation through an Akt1- and microRNA-155-dependent pathway during atherosclerosis. Circulation 127: 1609-1619, 2013.

18. Ramírez CM, Goedeke L, Rotllan N, Yoon JH, Cirera-Salinas D Mattison JA, Suárez Y, de Cabo R, Gorospe $M$ and Fernández-Hernando C: MicroRNA 33 regulates glucose metabolism. Mol Cell Biol 33: 2891-2902, 2013.

19. Hu J, Xu Y, Hao J, Wang S, Li C and Meng S: MiR-122 in hepatic function and liver diseases. Protein Cell 3: 364-371, 2012. 
20. Shirasaki T, Honda M, Shimakami T, Horii R, Yamashita T, Sakai Y, Sakai A, Okada H, Watanabe R, Murakami S, et al: MicroRNA-27a regulates lipid metabolism and inhibits hepatitis $\mathrm{C}$ virus replication in human hepatoma cells. J Virol 87: 5270-5286, 2013.

21. Xie Y, Tobin LA, Camps J, Wangsa D, Yang J, Rao M, Witasp E, Awad KS, Yoo N, Ried T and Kwong KF: MicroRNA-24 regulates XIAP to reduce the apoptosis threshold in cancer cells. Oncogene 32: 2442-2451, 2013.

22. Meloni M, Marchetti M, Garner K, Littlejohns B, Sala-Newby G, Xenophontos N, Floris I, Suleiman MS, Madeddu P, Caporali A and Emanueli C: Local inhibition of microRNA-24 improves reparative angiogenesis and left ventricle remodeling and function in mice with myocardial infarction. Mol Ther 21: 1390-1402, 2013.

23. Maegdefessel L, Spin JM, Raaz U, Eken SM, Toh R, Azuma J, Adam M, Nakagami F, Heymann HM, Chernogubova E, et al: miR-24 limits aortic vascular inflammation and murine abdominal aneurysm development. Nat Commun 5: 5214, 2014.

24. Murata K, Furu M, Yoshitomi H, Ishikawa M, Shibuya H, Hashimoto M, Imura Y, Fujii T, Ito H, Mimori T and Matsuda S: Comprehensive microRNA analysis identifies miR-24 and miR-125a-5p as plasma biomarkers for rheumatoid arthritis. PLoS One 8: e69118, 2013.

25. Livak KJ and Schmittgen TD: Analysis of relative gene expression data using real-time quantitative PCR and the 2(-Delta Delta $\mathrm{C}(\mathrm{T})$ ) method. Methods 25: 402-408, 2001.

26. Hansson GK: Inflammation, atherosclerosis, and coronary artery disease. N Engl J Med 352: 1685-1695, 2005.

27. Libby P, Ridker PM and Hansson GK; Leducq Transatlantic Network on Atherothrombosis: Inflammation in atherosclerosis: From pathophysiology to practice. J Am Coll Cardiol 54: 2129-2138, 2009.

28. Packard RR and Libby P: Inflammation in atherosclerosis: From vascular biology to biomarker discovery and risk prediction. Clin Chem 54: 24-38, 2008.

29. Chachaj A, Drozdz K and Szuba A: Reverse cholesterol transport processes and their role in artherosclerosis regression. Postepy Biochem 54: 301-307, 2008 (In Polish).

30. Hansson GK and Hermansson A: The immune system in atherosclerosis. Nat Immunol 12: 204-212, 2011.
31. Di Gregoli K, Jenkins N, Salter R, White S, Newby AC and Johnson JL: MicroRNA-24 regulates macrophage behavior and retards atherosclerosis. Arterioscler Thromb Vasc Biol 34: 1990-2000, 2014

32. Kelley JB, Talley AM, Spencer A, Gioeli D and Paschal BM Karyopherin alpha7 (KPNA7), a divergent member of the importin alpha family of nuclear import receptors. BMC Cell Biol 11: 63, 2010

33. Naqvi AR, Fordham JB, Ganesh B and Nares S: miR-24, miR-30b and miR-142-3p interfere with antigen processing and presentation by primary macrophages and dendritic cells. Sci Rep 6: 32925, 2016.

34. Xiang Y, Cheng J, Wang D, Hu X, Xie Y, Stitham J, Atteya G, Du J, Tang WH, Lee SH, et al: Hyperglycemia repression of miR-24 coordinately upregulates endothelial cell expression and secretion of von Willebrand factor. Blood 125: 3377-3387, 2015.

35. Liu XD, Wu X, Yin YL, Liu YQ, Geng MM, Yang HS, Blachier F and Wu GY:Effects of dietary L-arginine or $\mathrm{N}$-carbamylglutamate supplementation during late gestation of sows on the miR-15b/16, miR-221/222, VEGFA and eNOS expression in umbilical vein. Amino Acids 42: 2111-2119, 2012.

36. Rippe C, Blimline M, Magerko KA, Lawson BR, LaRocca TJ, Donato AJ and Seals DR: MicroRNA changes in human arterial endothelial cells with senescence: Relation to apoptosis, eNOS and inflammation. Exp Gerontol 47: 45-51, 2012.

37. Boon RA, Seeger T, Heydt S, Fischer A, Hergenreider E, Horrevoets AJ, Vinciguerra M, Rosenthal N, Sciacca S, Pilato M, et al: MicroRNA-29 in aortic dilation: Implications for aneurysm formation. Circ Res 109: 1115-1119, 2011.

38. Lal A, Navarro F, Maher CA, Maliszewski LE, Yan N, O'Day E, Chowdhury D, Dykxhoorn DM, Tsai P, Hofmann O, et al: miR-24 Inhibits cell proliferation by targeting E2F2, MYC, and other cell-cycle genes via binding to 'seedless' 3'UTR microRNA recognition elements. Mol Cell 35: 610-625, 2009.

39. Amelio I, Lena AM, Viticchiè G, Shalom-Feuerstein R, Terrinoni A, Dinsdale D, Russo G, Fortunato C, Bonanno E, Spagnoli LG, et al: miR-24 triggers epidermal differentiation by controlling actin adhesion and cell migration. J Cell Biol 199: 347-363, 2012. 